\title{
EL MOVIMIENTO DE LOS SIN-PAPELES COMO SUJETO DE JURIDICIDAD
}

\section{THE SINPAPELES MOVEMENT AS SUBJECT OF LEGALITY}

\author{
IKER BARBERO Iker.barbero@ehu.es \\ Universidad del País Vasco-Euskal Herriko Unibertsitatea. España
}

\begin{abstract}
RESUMEN
Desde un punto de vista formalista del Derecho, la producción de normas jurídicas está limitada a los poderes del Estado (legislativo, ejecutivo y judicial) así como a algunos agentes sociales legitimados por mecanismos de participación previstos en el ordenamiento jurídico. La capacidad normativa de agentes no reconocidos como sujetos de juridicidad únicamente puede ser investigada desde una perspectiva sociológica de la alternatividad del Derecho. Este texto presta atención a los actos de migrantes como sujetos de juridicidad, y especialmente a aquellos construidos social y normativamente como irregulares 0 autodefinidos como sinpapeles. A partir de la descripción de circunstancias sociales, jurídicas y políticas en torno a los encierros y otros actos de movilización que tuvieron lugar en Barcelona en el año 2001, se pretende analizar cuál fue la capacidad de los sin-papeles para incidir en la producción legal ya sea creando, modificando o alterando la agenda normativa en materia migratoria.
\end{abstract}

\section{Palabras Clave}

Barcelona; Derecho; Inmigración; Movimientos sociales; Prácticas alternativas.

\begin{abstract}
From a traditional perspective of Law, the production of legal rules is limited to State powers (legislative, executive and judiciary) as well as to some social agents legitimated through mechanisms of social participation foreseen in the legal system. The regulatory capacity of agents not recognized as subjects of legality can only be investigated from a sociological perspective of the alternativity of Law. This paper draws attention on acts of migrants, especially those irregular immigrants or sinpapeles as subjects of legality. Starting with an analysis of the social, legal and political context of the sit-ins and other acts of mobilization that took place in 2001, we will investigate the capacity of the sinpapeles movement in Barcelona to influence legal production either by creating, modifying or altering the policy agenda on migration.
\end{abstract}

\section{KEYWORDS}

Alternative Practices; Barcelona; Immigration; Social Movements; Law. 


\section{Presentación del Caso}

El día 20 de enero de 2001, la asamblea Papers per a Tothom o Papeles para todos, convocó una concentración abierta en la céntrica plaza de Cataluña de Barcelona para tratar la situación en la que se encontrarían las personas en situación documental irregular con la entrada en vigor el 23 de enero de la Ley de Extranjería, la L.O. 8/2000'1, y analizar cuáles podrían ser las estrategias tanto prácticas, en lo que a la regularización documental se refiere, como políticas, en referencia a aquellas estrategias de movilización y protesta.

El motivo principal era dar respuesta a la preocupación y temor que existían entre la población inmigrante en situación administrativa irregular, ya que el mensaje que se había hecho llegar desde instancias gubernamentales y a través de los medios de comunicación era que, además de eliminar derechos como los de reunión, manifestación o sindicación de todas aquellas personas carentes de los pertinentes permisos (Massó Garrote 2001; Sagarra 2001), estas serían detenidas, encarceladas y expulsadas del estado español, y por tanto del territorio Schengen, en cuestión de horas. Tal y como se podía leer en un periódico de tirada estatal,

"La ley de extranjería que hoy entra en vigor amenaza a 300.000 inmigrantes. [...] Los extranjeros que sean hallados en estas circunstancias podrán ser expulsados de forma preferente en 48 horas, 072 horas si se le aplica el procedimiento ordinario. [...] En las últimas fechas (el Estado español) ha negociado convenios de repatriación con los países con mayor flujo de emigrantes hacia España y está previsto que en breve estén suscritos con Nigeria, Colombia, Ecuador, República Dominicana, Rumania, Polonia y Senegal" (Diario El País, 23 de enero de 2001).

Esta sensación de tensión se hacía especialmente palpable en determinadas zonas. En Barcelona, el proceso de regularización extraordinaria que había tenido lugar entre el 23

\footnotetext{
${ }^{1}$ El objetivo de esta ley era la reforma de la anterior Ley Orgánica 4/2000, de Derechos y Libertades de los Extranjeros en España y su Integración Social, en aspectos sustanciales en lo que a reconocimiento de derechos a los extranjeros se refiere (independientemente de su situación documental administrativa) especialmente los más vinculados al desarrollo de la persona y su integración, como son los de participación social y educación. Pese a que aún preveía medidas sancionatorias contra las personas en situación irregular, esta ley mejoraba las garantías en materia de asistencia letrada, así como control jurisdiccional en los procedimientos de internamiento y retorno. La ley nacía del consenso entre los grupos de la oposición y es por ello intelegible que únicamente subsistiera durante el tiempo en el que el PP gobernó en minoría. En el momento en que alcanzó la mayoría absoluta, tal y como había mantenido durante la campaña electoral, anunció su reforma, evidentemente sin ni siquiera desarrollar el reglamento de la LO 4/2000. Este anuncio se vio reforzado con las constantes alusiones a la inseguridad provocada por el nuevo tratamiento de la inmigración.
} 
de marzo y el 31 de julio de $2000^{2}$, a diferencia de otras regiones, se estaba saldando con altas tasas de denegaciones. Concretamente, el $71 \%$ de las solicitudes cursadas en la provincia de Barcelona (más de 35.000 ) habían sido rechazadas, a diferencia de las provincias limítrofes, como Girona que apenas rondaba el 14\%, u otras como Madrid, con el $15 \%$. El temor de aquellas personas que habían visto rechazada su solicitud residía en que las notificaciones de denegación, que llegaban hacia finales de diciembre de 2000 y enero de 2001, adjuntaban también la notificación de inicio de proceso de expulsión por estancia en situación irregular.

En otros lugares del Estado también se dieron circunstancias específicas, como fue el caso de Lorca, en la región de Murcia. La muerte, el 3 de enero, de doce personas de origen ecuatoriano en un accidente de tráfico mientras se dirigían a trabajar como jornaleros sin contrato alguno, sacó a la luz pública la situación de explotación que sufrían los trabajadores del campo, no solo en Murcia, sino como característica estructural del sector (Martínez Veiga 2001; Pedone 2005). Si bien esta situación era notoria y contaba con impactantes antecedentes como el ocurrido en El Ejido el año anterior (Majuelos 2000; Checa y Olmos 2001; Martínez Veiga 2001), la atención mediática supuso prácticamente el cierre empresarial y la no contratación de inmigrantes por el temor a inspecciones gubernativas ${ }^{3}$. A los pocos días se produjeron las primeras reacciones de la población civil organizada de la región, mediante multitudinarias marchas (Montalbán 2003; Laubenthal 2005). Entre las principales demandas se solicitaban la admisión de la contratación excepcional, circunstancia que fue rechazada con rotundidad por el delegado del gobierno para la extranjería, Enrique Fernández Miranda, quien era firme partidario de atajar la irregularidad por la vía policial.

\footnotetext{
${ }^{2}$ Según informó a los medios de comunicación el delegado del gobierno, Fernández-Miranda, a fecha de 21 de diciembre 2000, de las 246.089 solicitudes presentadas hasta el 31 de julio del 2000 , fecha en la que finalizó el plazo de 4 meses, 137.454 eran admitidas, 82.845 denegadas y 6271 archivadas. El proceso de regularización del 2000 se fundamentó jurídicamente en la Disposición Transitoria Primera de la LO 4/2000 y el Real Decreto 239/2000, de 18 de febrero. Los principales requisitos que se exigían fueron encontrarse en España antes del 1 de junio de 1999 y haber permanecido de forma continuada en esa situación; Haber sido titulares de permiso de trabajo y/o residencia en los 3 años anteriores a la entrada en vigor de la Ley 0 haber solicitado permiso de trabajo y/o residencia antes del 31 de marzo del 2000; no haber existido contra el interesado resolución de expulsión vigente, ni estar incurso en causa de expulsión o prohibición de entrar en España, ni tener proceso penal en marcha; haber formalizado solicitud de asilo hasta 1 febrero de 2000 cuya petición esté en trámite o desestimada si reúnen los requisitos previstos en los apartados anteriores; 0 haber sido familiar de los extranjeros anteriores así como de los que residen legalmente en España siempre que reúnan los requisitos previstos en los apartados 1 y 3 .

3 "Los agricultores de Lorca se sienten abocados al fraude sistemático [...] Nuestra situación ahora es tan difícil como la de los inmigrantes", sostiene un finquero que prefiere no dar su nombre. "Nosotros los necesitamos a ellos y ellos a nosotros, pero el gobierno no quiere darles los papeles que les permitan trabajar nuestras tierras con todas las garantías". Diario El País, 7 de Enero de 2001.
} 
De hecho, la asamblea que se había convocado el 20 de enero en Barcelona, en parte, también se realizaba en solidaridad con las movilizaciones de Murcia, donde se comenzaban a producir los primeros encierros de inmigrantes en iglesias y otros edificios significativos. En un principio, la asamblea acordó realizar un encierro simbólico que tendría como escenario la catedral de Barcelona y que se limitaría al fin de semana. Sin embargo, ante la negativa de las autoridades eclesiales del templo, se acudió a Santa María del $\mathrm{Pi}$, una parroquia cercana donde el párroco Mosén Josep María Vidal Aunós, histórico colaborador con movimientos sociales, accedió a acoger a una representación de la asamblea. Finalmente, unas 350 personas lograron entrar a la segunda asamblea que se realizaría en la sacristía de la iglesia, y donde se decidió, no solo declarar indefinido el encierro, sino comenzar una huelga de hambre hasta que les fueran concedidos los papeles a todos. Comenzaba así el encierro de los sin-papeles en Barcelona.

\section{LA CONSTRUCCIÓN JURÍDICA Y SOCIAL DE LA CATEGORÍA DE LOS INMIGRANTES IRREGULARES}

La noción de sinpapeles surge en un momento concreto. La construcción de categorías diferenciadas a partir de normas sociales y jurídicas especiales ha sido estudiada desde múltiples ópticas, pero de un tiempo a esta parte ha recibido una atención especial en la construcción que las normas hacen de las categorías sociales a partir de la diferenciación entre ciudadanos, extranjeros o inmigrantes (Hammar 1990; Shuck 1998; Benhabib 2004; Bosniak 2008). No obstante, "ciudadanos", "extranjeros" o "inmigrantes", aunque a priori aparenten ser posiciones jurídicas y sociales absolutas, en realidad no son categorías excluyentes entre sí, sino necesitadas unas de las otras.

Así por ejemplo, Engin Isin, en su obra Being political: genealogies of citizenship (2002) sobre la construcción de subjetividades políticas a lo largo de la Historia, considera que el modelo de relación político-jurídica entre ciudadanos, extraños, foráneos y extranjeros en las sociedades contemporáneas, al igual que en otras épocas históricas, responde a lo que él denomina "lógicas de la alteridad" (P. 29). Para este autor, la relación entre esas categorías no seria inclusión o exclusión, sino una relación dialógica. Las formas de subjetividad política, como ciudadanos extraños, foráneos y extranjeros, no preexisten por sí mismas sino en relación unas con otras. Así, la construcción del inmigrante, incluida la del inmigrante en situación irregular, se produciría, al igual que las otras, a partir de una serie de estrategias, tecnologías y relaciones dialécticas a fin de crear un "otro" a quien gobernar desde una diferencia construida.

En una línea similar a la planteada por Isin, Balibar centra la construcción jurídica y social del "extraño absoluto" en una política concreta de los países del Norte global, la de fronteras $(2005 ; 2006)$. Se trata de un modelo que, además de emplear la tradicionales 
fronteras externas al territorio del Estado nacional, se sirve de un sistema de controles tanto en origen, para evitar la salida, como en destino, es decir, dentro del territorio estado nacional. En sus propias palabras: "bajo ningún concepto ciertas fronteras se hayan ya situadas en las fronteras en el sentido geográfico-político-administrativo del término, sino que residen en otro sitio, dondequiera que ejerzan controles selectivos" (2005:84).

Precisamente, en sintonía con la política desarrollada en el ámbito europeo (Huysmans 2000; De Lucas 2002; Blanco 2003; Monclús 2004; Rea 2006), la política migratoria y de extranjería española se ha caracterizado en los últimos treinta años por aspirar a compaginar un control fronterizo de flujos con proporcionar al mercado económico una mano de obra generalmente desregulada (Aja y Arango 2006; Calvita 2005); es decir, lo que podríamos denominar un "control selectivo" de la inmigración.

Por un lado, se ha establecido la dicotomía legalidad-ilegalidad, proporcionando a las autoridades las herramientas necesarias para perseguir, detener, encarcelar y expulsar a aquellas personas que, por la carencia de los permisos pertinentes, caían en esa categoría construida jurídicamente de "ilegales", con el añadido de que la indefinición del articulado dejaba lugar a la arbitrariedad administrativa y policial (Silveira 2003; Moya 2006); pero al mismo tiempo, la contratación de extranjeros se ha caracterizado por ser un mecanismo de contratación a la carta y bajo unas circunstancias de precariedad legitimada legalmente por esa construcción de la categoría de irregulares-ilegales (Martínez Veiga 20044; Blanco 2007; Solanes 2009). Dice De Lucas a este respecto que el derecho de extranjería, más allá de reconocer la presencia de ese "otro" para gestionarla,

"contribuye a los procesos que hacen de la inmigración sobre todo un objeto de regulación, control y dominación, como parte de un proceso de taxonomía (de teogonía) social, en un contexto muy preciso, el de la fragmentación y precarización del vínculo social, del que es emblema la degradación a escala global del estatuto del trabajador, del asalariado." (2008:217-218).

Relacionando esto con nuestro contexto de estudio, cabe decir que, al igual que sucedía en el resto del estado, la gran mayoría de los que optaron por comenzar la protesta en Barcelona compartía una característica común: ser considerados por la legislación de extranjería como inmigrantes ilegales y socio-laboralmente relegados a la clandestinidad.

\footnotetext{
${ }^{4}$ En su obra sobre la precariedad a la que se ven abocados los inmigrantes a los que se refiere como "trabajadores invisibles", Martínez Veiga describe con profundidad cómo sectores tan relevantes como la construcción, la agricultura, el trabajo doméstico o el sector servicios se nutrían básicamente de personas extranjeras africanas, latinoamericanas y asiáticas en situación documental irregular y sometidas a condiciones de perpetua temporalidad, precariedad y rotación.
} 
Se trataba principalmente de hombres y algunas mujeres de mediana edad, procedentes de Pakistán, India, Bangladesh, Marruecos, África Negra, Europa del Este y, en menor medida, de América Latina. Aquellos que procedían del África Negra, principalmente de Ghana, Nigeria, Senegal o Sierra Leona, habían estado casi un año acampados en la plaza Catalunya, después de que las autoridades les hubieran dejado en un limbo jurídico tras trasladarlos en avión desde las Islas Canarias adonde habían llegado por mar. Tal y como se podía leer en prensa,

"muchos subsaharianos que llegan a España [...] explican, se montaron en un barco de pesca que les llevó de Sierra Leona a Las Palmas. Allí fueron interceptados por la policía y recluidos en un centro de Interior durante 40 días. A continuación, los pusieron en la calle. Misteriosamente, una persona anónima les dio 37.000 pesetas para coger un avión a Barcelona." (Diario La Vanguardia, 2 noviembre de 2000).

Todos contaban con una orden de expulsión no ejecutable pero sin la posibilidad de regularizarse ni acceder a contratos de trabajo.

Las personas de Europa del Este, por su parte, también habían estado acampadas previamente en una plaza; en este caso la plaza Espanya Industrial. Como nos relataba una de las ocupantes de la plaza, y que posteriormente participaría en los encierros,
"Yo trabajaba en servicio doméstico, limpiando casas, y los hombres en la construcción, pero como no teníamos papeles ni contrato no teníamos derechos. Son trabajos duros y peligrosos. No puedes pedir seguridad en el trabajo y si tienes un accidente nadie te ayuda. Sólo te explotan. Mi jefa siempre me prometía hacerme un contrato pero nunca llegaba y claro, si te cambias de trabajo todo el mundo te pedía papeles. Si no tienes contrato no tienes papeles y si no tienes papeles no tienes contrato". (Ocupante de la plaza España Industrial y en el encierro de la iglesia de Sant Agustí).

A pesar de tratarse de causas y contextos distintos, ambos colectivos, africanos y europeos, confluyeron durante el año 2000 en una lucha bajo el lema "Papeles, vivienda digna y trabajo", en la que Papers per a Tothom jugó un papel importante. En una línea similar se encontraban los colectivos surasiáticos. Aunque habitaban desde hacia tiempo en la ciudad (Feixas 2007), su visibilidad social, y sobre todo política, era prácticamente nula, y no iba más allá de los establecimientos hosteleros, bazares y de la venta ambulante. De ahí que su aportación a las protestas fuera una sorpresa incluso para los organizadores de la asamblea informativa del 20 de enero.

En definitiva, los que participaron en los encierros eran lo que Terray ha denominado mano de obra "deslocalizada in situ" (1999), es decir, empleados en sectores en los que la deslocalización resulta imposible física y materialmente: construcción, distribución de publicidad, servicio doméstico, hostelería, etc. Aun así - a pesar de que la Ley de Extranjería 8/2000 no solo no reconociera a los inmigrantes irregulares como sujetos 
políticos al denegarles el derecho de reunión, manifestación o sindicación, sino que incluso los concebía como antijurídicos, ya que su mera estancia estaba sancionada por ley y perseguida por las fuerzas policiales, de cara a abordar la trascendencia jurídica, política y social de los encierros- podríamos plantearnos las siguientes preguntas: ¿Cómo unos sujetos no solo no reconocidos como actores en la esfera pública, sino además perseguidos por las normas de extranjería, fueron capaces de convertirse en sujetos políticos y jurídicos? ¿Hasta qué punto lograron modificar las circunstancias jurídicas, políticas y sociales?

\section{Prácticas alternativas para construirse como sujetos colectivos de JURIDICIDAD}

El paradigma jurídico y político fundamentado en la centralidad del estado en la producción normativa, también denominado "monismo jurídico", constituye hoy en día un argumento prácticamente dogmático. La profundidad con la que este modelo ha penetrado en la forma de percibir qué es el Derecho ha consolidado en el pensamiento moderno (Hobbes 1980; Locke 1988; Kelsen 1991 o incluso Weber 1985) la visión de cómo el Estado, en tanto que poder soberano, constituye la única fuente posible de creación jurídica.

No obstante, esta apreciación hegemónica sobre la producción del Derecho ha servido de base argumentativa para que, desde distintas disciplinas jurídicas, se elabore una crítica común que cuestione este modelo, tanto por su visión uniformizadora de ordenación política de la sociedad, como por su construcción mitificada del Derecho. Sus raíces se encuentran ya en el siglo XIX, en autores como Ehrlich, para quien el centro de gravedad del desarrollo del derecho no se encontraba en la legislación ni en la ciencia jurídica, ni en la jurisprudencia, sino en la sociedad misma (2005), o Gurtvich, según el cual el Estado no es otra cosa que "un pequeño lago profundo en el inmenso mar del Derecho que lo circunda por todas partes" (en Treves 1988:118). No obstante, es a finales del siglo XX cuando distintas corrientes socio-jurídicas enmarcadas en lo que se ha denominado "pluralismo jurídico" (Griffiths 1986; Merry 1988) han proporcionado los elementos necesarios para encuadrar las prácticas y discursos desarrollados por los colectivos no pertenecientes al aparato estatal. 
Dentro del amplio fenómeno del pluralismo jurídico ${ }^{5}$, existe una serie de estudios centrados en prácticas jurídicas denominadas, en sentido genérico, "alternativas", que suceden dentro y fuera del campo jurídico estatal y que tienen por objetivo lograr un mayor acceso a la justicia, generar conciencia y organización popular, en definitiva, cuestionar, transformar, los fundamentos jurídicos y sociales dominantes. Se trataría al mismo tiempo de un ataque a la concepción formalista del Derecho como a la concepción tradicional de neutralidad de la ley. El Derecho no es un mecanismo aséptico de regulación social, sino que tanto sus formas (monopolio estatal de producción, procedimientos legislativos y jurisdiccionales) como sus componentes ideológicos que subyacen bajo las normas, pueden constituir elementos empleados en la dominación y control social.

La diversificación de los modos de producción de Derecho se manifiesta mediante vías jurídicas y políticas tanto formales como informales. La teoría del Derecho alternativo recorre toda una serie de actuaciones y localizaciones por las cuales los sujetos en cuestión inciden de manera directa en la elaboración normativa (Palacio 1993; Herrera y Sánchez 1993; Carvalho 1997). Así, por un lado, encontraríamos las decisiones judiciales tomadas por miembros progresistas de la judicatura dirigidas a enmendar situaciones desfavorables, lo que ha sido históricamente calificado como "uso alternativo del Derecho" (Carvalho 1992); por otro lado, también se refiere a distintas actuaciones de juristas comprometidos en la defensa de grupos desfavorecidos (Burgos 1996). Y finalmente, hace mención a lo que algunos autores han denominado el Derecho "de la calle" (Santos 1977; 1992), "Derecho alternativo puro" (Bergalli 1992) o "insurgente" (Rech 1990) como "el nuevo Derecho creado por los oprimidos de acuerdo con sus intereses y necesidades, inserto o no en las leyes vigentes y rescatado a través de la formalización para que sea reconocido como un Derecho vigente" (1990:5).

Partiendo de esta perspectiva, Antonio Carlos Wolkmer viene trabajando sobre la idea del "Nuevo Paradigma Social de Producción Normativa" -NPSPN- (1991; 1994; 2006). Wolkmer opta por una noción de pluralismo jurídico destinado a reconocer y legitimar normas producidas a través de canales formales, pero sobre todo informales, que tienen lugar en un mismo espacio jurídico, político y social, y que son fruto de las acciones y reivindicaciones de nuevos sujetos colectivos que sufren las carencias y

\footnotetext{
${ }^{5}$ Más allá de los estudios clásicos en contextos coloniales y primitivos (Malinowsky 1969; Pospisil 1971), resultan interesantes para este texto aquellos estudios sobre la pluralidad de sistemas normativos en contextos complejos e industrializados que comienzan a analizar las distintas normativas, códigos internos 0 sistemas de resolución de conflictos empleados por grupos étnicos, comunidades religiosas, asociaciones mercantiles, o incluso organizaciones criminales (Moore 1973; Santos 1977; Merry 1979; Galanter 1981 o Facchi 1994). Ver el excelente estudio preliminar realizado por Libardo Ariza y Daniel Bonilla (2007) en el que recogen las distintas corrientes, así como las tendencias contemporáneas en las que se encuentra el pluralismo jurídico.
} 
necesidades a causa de la desigualdad estructural y exclusión jurídica características en sociedades del capitalismo (semi)periférico. El NPSPN es un concepto que resulta útil a la hora de intentar responder a alguna de estas cuestiones relacionadas con el movimiento sin-papeles, desde el momento en que se aproxima a aquellos segmentos sociales excluidos de los centros de decisión, pero que, sin embargo, mediante prácticas alternativas logran autoorganizarse, movilizarse e incluso incidir en la producción normativa. Concretamente, Wolkmer emplea la noción de "nuevos sujetos colectivos de juridicidad" delimitados estos como

"identidades colectivas conscientes, más o menos autónomas, advenidas de diversos estratos sociales, con capacidad de autoorganización y autodeterminación, interrelacionadas por formas de vida con intereses y valores comunes, compartiendo conflictos luchas cotidianas que expresan privaciones y necesidades de derechos, legitimándose como fuerza transformadora del poder en instituidora de una sociedad democrática, descentralizadora, participativa e igualitaria." (2006:211).

Según este autor, las nuevas identidades las componen una constelación de múltiples subjetividades colectivas como campesinos sin tierra y los emigrantes rurales, obreros mal remunerados y explotados, organizaciones comunitarias, marginados de las concentraciones urbanas, poblaciones indígenas amenazadas y exterminadas, mujeres que sufren todo tipo de violencia y discriminación, grupos étnicos y así un largo etcétera. Por ello que la emergencia de estos movimientos sociales responda principalmente, según Wolkmer (2006), a la crisis de legitimidad en el paradigma contemporáneo de la representación política (p. 128). La paulatina inadecuación de los canales formales clásicos de legitimidad para canalizar y responder a las demandas sociales convierte a los movimientos sociales en artífices de un estilo de política pluralista. Por medio de prácticas no institucionales sino basadas en valores y formulaciones jurídicas y políticas comunitarias tiene lugar la nueva "legitimidad", e incluso una nueva "legalidad".

Por otra parte, desde el momento en que se constituyen en sujetos colectivos, a pesar de la inevitable injerencia de otros campos jurídicos, los movimientos sociales cuentan con su propia autorregulación marcada por un pretendido perfil antitético al formalismo institucional. A pesar de las posibles ambigüedades y contradicciones internas, dice Wolkmer, este perfil se caracteriza por ser mínimamente institucionalizado, informal, flexible y no autoritario sino descentralizado, derivado de la identidad autónoma y emancipadora (2006:131).

Al trascender, tanto los procedimientos formalizados desarrollados por los mecanismos de representación delegada, como las estructuras jerárquico-institucionales internas, los movimientos sociales amplían el espacio de interacción pública definiendo, así, nuevas formas de juridicidad. La innovación de estas maneras alternativas de producción jurídica no reside necesariamente en el contenido de las demandas ni en las consecuencias jurídico-normativas en las que pueden derivar, sino que para 
Wolkmer, la novedad está "en que el modo de obtención de derechos ya no pasa por las vías tradicionales -legislativas y judiciales- sino que proviene de un proceso de luchas y conquistas de las identidades colectivas para el reconocimiento por parte del Estado" (2006:149).

En definitiva, la lucha por el reconocimiento de derechos se ha vinculado al uso alternativo del Derecho así como a la producción alternativa. Múltiples sujetos y grupos han sido fuente de juridicidad, ya sea en un sentido conservador como progresista. Especialmente en Latinoamérica, pero también en muchos otros rincones del mundo (Santos y Rodríguez 2007), clases marginales se han constituido en colectividades autoorganizadas con el fin de adquirir capacidad normativa e intervenir-irrumpir en procesos de decisión para transformar el ordenamiento jurídico y el entorno social.

Por tanto, debemos preguntarnos si estaríamos ante la emergencia de nuevos sujetos colectivos, con propósitos de transformación jurídica, política y social. Seguramente haya muchos colectivos candidatos a esta categoría (mujeres, campesinos, indígenas, homosexuales...). Sin embargo, a efectos de este trabajo, la cuestión que se nos presenta es esta: ¿son los inmigrantes con y sin-papeles que se movilizan en las ciudades del norte los protagonistas de prácticas alternativas de ciudadanía? De esta forma, en lo que sigue, analizaremos como la construcción jurídica, política y social de los inmigrantes irregulares a partir de las privaciones legales de derechos, persecución policial así como condiciones de precariedad laboral localizan un escenario desde el cual indagar desde la praxis si es preciso considerar las nuevas formas de respuestas o resistencias de los inmigrantes sin-papeles como expresiones de una nueva legalidad.

\section{La obtención de información para el estudio de los encierros}

La primera labor que se realizó fue hacer un sondeo sobre lo que se había investigado sobre el tema. Apenas existían estudios sistematizados, como pueden ser tesis doctorales ${ }^{6} 0$ estudios académicos en profundidad, sino más bien únicamente artículos académicos 0 de divulgación sobre el caso de los encierros de 2001 en Barcelona ${ }^{7}$ así

\footnotetext{
${ }^{6}$ Recientemente, y de forma paralela a nuestra investigación, ha sido defendida la tesis "Porque la ciudadanía se consigue ejerciéndola..." Una aproximación sociológica al proceso instituyente del movimiento de migrantes en Barcelona (2010) sustentada por Amarela Varela en la Universidad Autónoma de Barcelona en la que hace un recorrido histórico de los distintos momentos de las luchas migrantes en la ciudad, centrándose más en aspectos sociales y políticos que jurídicos.

${ }^{7}$ Artículos en revistas especializadas y ediciones especiales han sido de gran utilidad, como son los publicados en la revista Mugak, concretamente en el número 14, La irrupción de los sin-papeles; el artículo de Marco Aparicio "Los encierros de inmigrantes sin-papeles: la experiencia de Barcelona" (2002), quien además fue abogado y activista durante los encierros; "Praxis ciudadana de los excluidos: el caso de los sin-papeles" (2005) de Anna Alabart; finalmente, la recientemente publicada Las luchas de los sin-papeles y la extensión de la ciudadanía. Perspectivas críticas desde Europa y Estados Unidos (2007), editada por Liliana Suárez-
} 
como otros escenarios donde también tuvieron lugar protestas similares ${ }^{8}$.

La fuente de información más relevante ha sido la documental, ya que permaneció inalterada en el tiempo. Así, además de las normas jurídicas (directivas comunitarias, leyes orgánicas de extranjería, reglamentos, instrucciones administrativas, etc.), se estimó primordial incluir aquellos documentos que no fueron emanados directamente de ninguna norma jurídica positiva, sino que provenían de los propios inmigrantes sinpapeles, en tanto que sujetos no identificados como operadores jurídicos en sentido estricto (De Lucas 1992). El motivo de la inclusión reside en que estos documentos gozan de un alto contenido jurídico en lo que a su discurso y simbología se refiere, cuya pretensión era precisamente la creación, modificación o eliminación de normas jurídicas, y cuya presencia en un contexto social concreto tuvo consecuencias jurídicas. Ejemplo de ello son los comunicados donde los distintos colectivos y movimientos sociales expresaban sus demandas o reivindicaciones, los documentos emanados de las negociaciones resultantes del conflicto, los mensajes plasmados en las pancartas o los manifiestos elaborados al hilo de acciones o prácticas jurídicas alternativas, así como los textos y actos jurídicos generados durante el propio encierro: el acuerdo de Barcelona de 8 de marzo de 2001.

Respecto a las entrevistas realizadas, tanto informativas como en profundidad a las personas fueron seleccionadas por su relevancia o relación con el objeto de estudio: miembros del movimiento sin-papeles, juristas y abogados, así como miembros de otros movimientos sociales involucrados. El objetivo era obtener datos y, al mismo tiempo, discursos sobre la vivencia y sensaciones percibidas durante el encierro, y las motivaciones que derivaron en los actos de protesta.

Finalmente, es necesario añadir que, si bien propiamente, no podemos decir que se realizó observación directa ni participante, sí se ha dispuesto de elementos observados y situaciones vividas durante la investigación que no pueden ser desechadas. Nos estamos refiriendo a documentos audiovisuales ${ }^{9}$, los cuales nos han permitido mirar a

Navaz, Raquel Macià Pareja y Ángela Moreno García; donde se recogen una serie de textos relativos a las distintas experiencias protagonizadas por inmigrantes sin-papeles en distintos lugares del mundo.

${ }^{8}$ En relación a otros escenarios de movilizaciones coetáneos, se han publicado textos como pueden ser el artículo de Francisco Torres "Logros, límites y problemas" (2001) sobre los encierros en Valencia; el artículo de Danielle Provançal y Pedro Molina, "La hospitalidad a prueba: migrantes en Almería" (2002), sobre los encierros en la Universidad de Almería; la obra de Federico Montalbán López, Inmigrantes en lucha. Región de Murcia 2001 (2003) o la de Laubenthal, "La emergencia de las protestas de inmigrantes sin-papeles en España: el caso de la Región de Murcia" (2005) sobre las luchas de los inmigrantes en Murcia.

${ }^{9} \mathrm{El}$ análisis de prensa, a la vez que ofrecía información escrita, también incluía imágenes y dibujos de los distintos momentos de los encierros que permitían obtener otro tipo de datos: los escenarios, los cuartos de las iglesias, las fachadas donde se colgaban las pancartas, los carteles de las manifestaciones, los movimientos; así como poner caras a las personas de las que se hacia referencia en los textos. Algo similar sucede con los vídeos de los servicios informativos televisivos. Así mismo se consiguió elaborar una selección, con 
través del tiempo y llegar a los protagonistas y a los escenarios, tal y como lo captaron las cámaras en su momento; así como participación en asambleas y protestas posteriores con cierto grado de similitud al caso estudiado.

\section{LOS SIN-PAPELES COMO SUJETOS DE JURIDICIDAD}

Un punto de partida para el análisis puede ser la concepción de las protestas de los sin-papeles como un movimiento colectivo y simultáneo. En este sentido, podemos dar cuenta de la emergencia de una conciencia colectiva y simultánea entre los distintos movimientos de inmigrantes sin-papeles que está teniendo lugar tanto en el contexto europeo como en el americano (Aierbe 2000; Cissé 2000; Coutin 2000; Krueger 2001; Laubenthal 2007; Nyers 2008; Suarez et al. 2008). Dadas las circunstancias de control y persecución de la inmigración, la obtención de los permisos se había convertido en una cuestión vital para muchas personas. Para el caso del movimiento sin-papeles, este anhelo ha pasado de ser un sueño individual a una meta política que aúna a quienes se encuentran bajo el dictado de las leyes de extranjería. De ahí que la denominación "sin-papeles" haya dotado de sentido identitario al grupo y de legitimidad para actuar como sujetos políticos. Debemos considerar al movimiento sin-papeles como nuevo sujeto colectivo desde el momento en que se autodeterminan como tal y se consideran legitimados para plantear sus propias demandas:

"Los papeles es lo que nos piden siempre, cuando trabajamos, cuando caminamos... como no los tenemos, nos autodenominamos sin-papeles que, aunque no sea un término legal, nos parece mucho más real que ilegales 0 irregulares. Algunos abogados nos dicen que es un término alegal que nos ubica en un limbo. A nosotros nos gusta porque nos sirve de plataforma desde la cual reclamar los derechos más elementales que las leyes nos niegan." (Representante de Papers per a tothom).

Esta reflexión preliminar en torno a la consideración del movimiento de sin-papeles como los sujetos colectivos nos sitúa en un plano de análisis a partir del cual abordar la cuestión de las luchas en Barcelona en 2001 como nuevo paradigma social de producción jurídica, desde una triple perspectiva.

- En primer lugar, sería necesario prestar atención a lo que podríamos entender como la autoorganización u "organización interna" de lo que supusieron los encierros en las iglesias;

más de 35 minutos de duración, de algunos telediarios de la televisión pública catalana TV3, en los que se ofrecían cada día noticias, imágenes y comentarios sobre la evolución de los encierros, etc. 
- Es relevante mencionar, en segundo lugar, cuáles son las principales expresiones de "movilización exterior" que tuvieron lugar paralelamente a los encierros.

- En tercer lugar, nos centraremos en las "consecuencias jurídicas" de las luchas, especialmente en lo que se denominó "Acuerdo de Barcelona", no tanto como paradigma de plenitud emancipadora, sino como, al menos, una manifestación empírica de la incidencia, parcial y puntual, pero real, en la producción normativa de sujetos no legitimados.

\section{Organización interna}

Anteriormente hablábamos de Papers per a Tothom como la convocante de la asamblea que desembocó en la ocupación de la iglesia de Santa María del Pi, sin embargo, como dijo uno de los representantes de la organización, "con el comienzo del encierro, la asamblea se diluyó" dando lugar una nueva forma de organización que tomó las riendas de la lucha y los militantes de la Asamblea se reubicaron asumiendo distintos roles.

Aunque la iglesia Santa María del Pi fue el centro neurálgico de la lucha, donde se realizaban las principales acciones, a medida que avanzaban los días, la afluencia de "sinpapeles" que deseaban sumarse al encierro hizo que entre los representantes y el párroco de la iglesia buscaran otros espacios a los que expandir la protesta, principalmente hacia iglesias donde los párrocos que las regentaban también simpatizaban con la causa de los "sin-papeles". Así se fue conformando una red de hasta "once encierros" en iglesias distribuidas por el área metropolitana de Barcelona, concretamente en los municipios de Barcelona y de Cornellá del Llobregat ${ }^{10}$. Cada una de estas iglesias se organizaba de manera asamblearia semiautónoma en coordinación con la "Asamblea General" que se reunía en la Iglesia del $\mathrm{Pi}$.

En la Asamblea General participaba cada una de las iglesias, las comunidades de inmigrantes, así como otros actores que se involucraron de manera directa en los encierros. Ésta tenía lugar en la nave principal del templo en aquellos momentos en los que no se celebraban actos religiosos. A pesar de que la figura de los líderes comunitarios fue la más predominante, durante las asambleas, se procuraba que todo el mundo tuviera la oportunidad de plantear su posición 0 , al menos, comprendiera los aspectos fundamentales del debate. De ahí que, a pesar de los problemas de tiempos y fuerzas que supo-

\footnotetext{
${ }^{10}$ Por orden cronológico, la primera en abrirse fue la de Santa María del Pi, que acogió al menos a 350 inmigrantes, y un par de días más tarde la de Sant Agusti, unas 40 personas. En un mismo día, el 23 de enero, se abrieron tres: Mare del Carme, donde se alojaron una veintena; Sacrat Cor, otras 25 personas, y Sant Pere Claver, que acogió 35. Y en días sucesivos se fueron abriendo las iglesias de Sant Pere Apostol, donde ya estaban siendo acogidos los africanos de Plaza Catalunya; Sant Medir, que dio asilo a unas 45 personas; la Medalla Miraculosa, con 35 personas; Santa Engracia, con una veintena; la Parroquia del Pilar de Cornellá del Llobregat, donde la cifra rondaba los 100 encerrados; y finalmente la de Sant Pau del Camp, donde, pese a ser un encierro abierto, fueron unas 15 mujeres las que se mantuvieron encerradas.
} 
nía, todas las intervenciones de las asambleas, así como los comunicados, manifiestos y documentos públicos se traducían a las principales lenguas empleadas en el encierro, principalmente catalán, español, inglés, francés, amazigh, árabe, urdú, bengalí, wolof, hindi, ruso, búlgaro o rumano.

Estas tareas de traducción, así como las de limpieza, asistencia sanitaria, propaganda, jurídica, prensa 0 avituallamiento, las realizaban grupos de personas voluntarias que de forma espontánea 0 a petición de los representantes iban constituyéndose en lo que se denominaron "comisiones delegadas". Dando por supuesto el incalculable valor que para el mantenimiento de los encierros y la huelga de hambre supusieron todas las comisiones, la que, sin duda, fue una comisión clave en todo el proceso fue la negociadora. Compuesta por una representación elegida por los inmigrantes encerrados, los integrantes de la comisión se reunieron directamente con instituciones como el Síndic de Greuges (defensor del pueblo catalán) a lo largo de los 47 días que duró el encierro. De estas reuniones salieron documentos clave en las negociaciones para la resolución del conflicto.

\section{Movilización exterior}

Además de la autoorganización del encierro, la movilización de la sociedad civil y las muestras de solidaridad exteriores fueron pilares fundamentales para la consecución de las reivindicaciones planteadas.

Todas las necesidades que se generaron durante esos 47 días de encierro y durante la quincena que duró la huelga de hambre (mantas, colchones, ropa limpia, botellas de agua, dinero, y otros bienes de primera necesidad) fueron satisfechas mediante la aportación ciudadana. La asistencia sanitaria fue cubierta desde un primer momento por los y las voluntarias de la comisión sanitaria, a la que posteriormente se sumaron organizaciones como la Cruz Roja. La labor del personal médico voluntario fue esencial, especialmente durante los momentos más críticos de la huelga de hambre donde los desfallecimientos eran habituales.

Es conveniente matizar el relevante papel que desarrolló la Iglesia católica, dentro de la cual se pudieron observar posturas diferenciadas. Como organización se resume en la frase de Arcadi Oliveres (Justicia i Pau) durante la entrevista: "en aquel momento, lo que son las jerarquías de la iglesia, ante los encierros, no hubo intervención, pero tampoco, salvo algunas presiones, hubo oposición. Los que se portaron de manera excelente fueron la iglesia de base, especialmente los párrocos de las iglesias del Pi, Mossen Vidal y Mossen Bigorda". Está diferenciación entre alta jerarquía eclesial e iglesia de base es imprescindible para entender los encierros de Barcelona, y tal vez otros del Estado. Mientras las altas esferas jerárquicas mostraron una postura de no intervención políticamente correcta, la iglesia de base, organizada en torno a colectivos sociales como Justicia i Pau, la Pastoral Obrera, Cáritas, la Juventud Obrera Cristiana o la Unió de Religiosos de Catalunya, aportó su colaboración ofreciendo locales, llamando a las movilizaciones o ejerciendo el papel de garantes de los acuerdos como veremos más adelante. 
Los apoyos y movilizaciones sociales más de carácter político los encontramos en organizaciones y grupos de diversa naturaleza. Es necesario mencionar en un primer lugar a la Plataforma de Suport als Immigrants en Lluita o Plataforma de Apoyo a los Inmigrantes en Lucha. En esta plataforma participaban además de Papers per a Tothom, sindicatos, grupos de estudiantes asamblearios, miembros del movimiento okupa, feministas, zapatistas, colectivos de abogados, diversas ONG y partidos políticos extraparlamentarios así como otras organizaciones próximas a las ideologías de izquierda más alternativa ${ }^{11}$. Muchas de ellas llevan desde hace años defendiendo en sus reivindicaciones cotidianas y trabajando a favor de objetivos como la derogación de las leyes de extranjería y la defensa de la apertura de las fronteras o libertad de circulación. Junto a esta plataforma, también jugó un papel relevante la Plataforma per la Ciudadania i la Convivència o Plataforma para la Ciudadanía y la Convivencia que estaba formada principalmente por organizaciones que también contaban con una larga trayectoria en el ámbito de la integración social y laboral de los extranjeros y en la lucha contra el racismo ${ }^{12}$. Sin embargo, su principal diferencia con respecto a la otra plataforma era su visión de la gestión de los flujos migratorios, defendiendo una política de regulación y, por tanto, control de los flujos migratorios y el establecimiento de una ley de extranjería de mínimos. Estas diferencias ideológicas entre las distintas plataformas fueron la causa y la consecuencia de las tensiones que afloraron a lo largo de los encierros, especialmente en lo que a las grandes manifestaciones se refiere.

${ }^{11}$ Las organizaciones A.P.A. sin fronteres (Ripollet), Agermanament, Asamblea de Gavá contra la Globalización, Asociación Ética y Societat civil, ATTACC, Casa de la Reconciliación, Casa Retruco, Col.lectiu Ronda, Collectius de solidaritat amb la rébellió Zapatista, Comissió de Cultura de Can Serra, Comissió de Defensa deis Drets Humans (Collegi d'Advocats de Barcelona), Comité de Suport al MST (Barna), Entredobles, Federeacion de Asociaociones de Vecinos de Barcelona, Federecion de Colectivos de Inmigrantes de Catalunya, Fundació Intermon, Grup de Dones de Can Serra, Xarxa Mundial de Dones (Bama), Mesa Cívica del Drets Socials, Mujeres por un salario para el trabajo sin sueldo, Papers per a tothom, Parroquia Sant Benet, Plataforma en Defensa deis Menors Immigrats Desemparats, Plataforma Solidaritat Gent Immigrant (Badalona), Regidoría de Drets Civils (Ajuntament Bama), Revista Viejo Topo, Riebapua, Salario debido a las Lesbianas, SETEM, UMCEC o Vaga Mundial de Dones 8-M-2001; los partidos políticos como Balzac, Colectivo por una Izquierda Alternativa de la VI Internacional, Els Verds, Ezquerra Republicana de Catalunya, Ezquerra Unida i Alternativa, Joves Comunistas, Partido Obrero Revolucionario, Partido Obrero Socialista Internacionalista, Partido Revolucionario de los Trabajadores o el Partit Socialista Unificat de Catalunya; o sindicatos como CATAC, CATAC-Sanitat, CAU, CGT, CNT-AIT, IAC (USTEC-STEs), Sección Sindical CC.OO de Miniwat o USOC.

${ }^{12}$ Comisiones Obreras, UGT, SOS Racisme, Amnistía Internacional, Médicos sin Fronteras, Càritas, Iniciativa per Catalunya-Vers, Ezquerra Republicana o el Partido Socialista de Cataluña, principalmente. Dentro de cada plataforma además había organizaciones como la Federación de Asociaciones de Vecinos (FAVB), Esquerra Unida i Alternativa (EUiA) o la Federació de Col-lectius d'Immigrants de Catalunya (FCIC) que debido a las opiniones internas diversas contaban con representantes en ambos sitios. 
Además de numerosas concentraciones reivindicativas, asambleas informativas y otros actos de desobediencia civil que se realizaron durante los casi cincuenta días que duraron los encierros, tuvieron lugar dos grandes manifestaciones. La primera, celebrada el 26 de enero, apenas unos días después del inicio del encierro y la huelga de hambre, congregó a 5000 personas frente a la Delegación del Gobierno, en Barcelona. A esta concentración acudieron numerosos políticos, sindicalistas, personalidades del ámbito académico, estudiantes, inmigrantes con y sin-papeles, y tras la cual, a instancias de los representantes de los inmigrantes en lucha, se improvisó una manifestación hasta la plaza del $\mathrm{Pi}$, durante la cual se corearon consignas como "Ninguna persona es ilegal" o "Fuera la ley de extranjería".

La segunda gran manifestación tuvo lugar el 4 de febrero en la que 50.000 personas secundaron la llamada de los organizadores para reclamar la regularización de los sinpapeles en una marcha que llevaba el lema: "Por el reconocimiento de los derechos y la dignidad de los inmigrantes". Fue durante los encuentros preparativos de ésta cuando surgieron con más claridad las principales divergencias entre las dos plataformas antes mencionadas, especialmente en lo que se refería a la conveniencia de la utilización de métodos de lucha como la huelga de hambre, como defendía la Plataforma de Apoyo a los Inmigrantes en Lucha, y al apoyo a la manifestación condicionado a la finalización de esta medida, como sostenía la Plataforma para la Ciudadanía y la Convivencia. Finalmente, el llamamiento a la manifestación del 4 de febrero, titulado "Solidaridad con los inmigrantes en lucha", omitiendo el motivo de desencuentro entre plataformas, significaba un discurso de rechazo a la diferenciación a través de categorías jurídicas y sociales y la construcción de la inmigración irregular:

"Categorías jurídicas como "extranjero" son, cada vez más, una forma que tienen los Gobiernos y la patronal de intentar dividir a la gente de este país. Quieren diferenciar entre "nacionales" y "extranjeros", institucionalización de las expulsiones, los centros de internamiento, la discriminación laboral etc., como medidas de castigo para las personas inmigrantes, especialmente aquellas sin-papeles. Para el Poder será más fácil dominarnos día a día si la gente estamos dividida en etiquetas como ésta. [...] ¿Queremos una Europa Fortaleza racista y egoísta que permite el paso de mercancías y capital pero levanta muros que impiden la libre circulación de personas (a no ser que tengan dinero)?".

La marcha partió de la plaza Catalunya bajo consignas como "papeles para todos" y con numerosas pancartas con lemas como "Centros de internamiento, centros de exterminio", "todas las personas somos inmigrantes" o "fuera la ley de extranjería", se realizó en constante ambiente reivindicativo-festivo ${ }^{13}$.

\footnotetext{
${ }^{13}$ La cantautora Marina Rossell puso fin al acto interpretando la Canción del emigrante. A la noche
} 


\section{Consecuencias jurídicas}

Las prácticas alternativas de carácter reivindicativo tuvieron su evidente influencia en el proceso de negociación que tuvo lugar entre los inmigrantes sin-papeles y diversas instituciones. Su análisis se reviste de relevancia desde el momento en que, como hemos dicho anteriormente, se trata de determinar si los sin-papeles incidieron en la producción normativa en materia de extranjería. Atendiendo al ritmo de las negociaciones, los actores involucrados, y los resultados positivos y negativos en los que resultaron, se pueden establecer cuatro momentos relevantes.

El primero es el referido al que va desde el planteamiento de las demandas hasta el inicio de las negociaciones con el Síndic. Desde el primer día en que comenzó el encierro se plantearon tres reivindicaciones políticas básicas:

1. la no aplicación de sanciones, como la deportación a los países de origen o la persecución a las asociaciones que apoyasen a colectivos de inmigrantes sinpapeles;

2. el cese del acoso policial;

3. y la regularización de los inmigrantes sin-papeles que se encontraran en el Estado español.

Estas fueron las demandas que se trasladaron a instituciones como la Delegación del Gobierno, o a la Generalitat de Cataluña, quien también actuaría en un principio como mediadora. A cambio del cese de la huelga de hambre, la oferta institucional se limitaba a legalizar la situación de quienes hubieran presentado la solicitud en el proceso de regularización anterior y la única causa de denegación fuera no haber podido demostrar que se encontraban en el país desde antes del 1 de junio de 1999, tal y como se recogía en la disposición adicional de la Ley de Extranjería que entraría en vigor en unos días. Esta oferta fue rechazada de pleno por los inmigrantes ya que ni se ajustaba a las demandas ni respondía a las circunstancias personales de la mayoría de los encerrados.

se celebró una fiesta en la rambla del barrio de El Raval, donde actuaron numerosos artistas, entre ellos, Manu Chao, la Companyia Elèctrica Dharma, Radio Raheem, Ojos de Brujo, Camàlics y cantantes como Paco Ibáñez, Rosa Zaragoza, Adolfo Osta o Cheb Balowski. La presencia de artistas durante los encierros fue constante. Desde los primeros días numerosas personas del mundo de las artes escénicas, plásticas y musicales se acercaron a las iglesias, principalmente a la del Pi a mostrar su apoyo y solidaridad con los inmigrantes en lucha. Por allí pasaron Paco Ibáñez y María Rossell quienes entregaron el Manifiesto de apoyo de la Associacio de Cantants y Interprets en Llengua Catalana ( $\mathrm{ACIC}$ ), y llegaron a tocar varias canciones entre las que cabe destacar la emblemática $A$ galopar, del poema de Rafael Alberti, que fue un símbolo de la libertad en la lucha antifranquista. 
Gracias a la implicación de juristas de la Comisión de Defensa de los Derechos de la Persona y del Libre Ejercicio de la Abogacía del Colegio de Abogados de Barcelona se realizó una primera adecuación de las reivindicaciones al marco jurídico, tal y como demandaba el Gobierno. Este hecho se produjo en los comunicados y documentos presentados públicamente los días 27 y 28 de enero, en los que la "Asamblea del Pi" demandaba que:

- Se ampliarán al máximo los supuestos de revisión de oficio de las denegaciones de regularización presentadas en persona por no cumplir el trámite de justificar la estancia en España antes de 1 de junio de 1999, incluyendo a aquellas afectadas por un proceso judicial por falsificación de documentos ("entendiendo que dichas personas no son inductoras de delito de fraude sino víctimas del mismo").

- La urgente asignación de un presupuesto especial y la contratación necesaria de personal para solventar las demoras en las tramitaciones de concesión de permisos de residencia y trabajo.

- La garantía de concesión de permiso de residencia por circunstancias excepcionales, habida cuenta de las condiciones humanitarias para aquellos que no cumplieran los requisitos anteriores.

- Que no se realizaran detenciones, sanciones ni expulsiones para los participantes en el encierro.

La cuestión era concretar sin perder la máxima "papeles para todos", por un lado, y sin llegar a la individualización extrema donde las demandas colectivas se difuminaran, por otro:

\footnotetext{
"Si haces unas demandas muy maximalistas que no consiguen nada, se acaba desinflando y acaba desarticulando, desgastando y dividiendo el movimiento sin resultado. Se llegó a un proceso de negociación basado en interpretaciones muy concretas de la ley que, si bien abrió una pequeña grieta, también hubo quien quedó fuera y eso fue muy duro porque al concretar al máximo, al final el Estado hace casuística de algo que era un movimiento colectivo". (Entrevista con abogado activista).
}

Sin duda, un segundo momento muy importante en la resolución del conflicto fue la petición del Secretario de Estado para la Extranjería y la Inmigración, Enrique FernándezMiranda, al Síndic de Greuges, Antón Cañellas, para que interviniera en calidad de mediador entre el Gobierno y los ya 600 inmigrantes sin-papeles encerrados en varias iglesias de Barcelona. Durante la serie de reuniones y contactos mantenidos entre el Síndic y los representantes de los encerrados las "circunstancias excepcionales" y las "razones humanitarias" se convirtieron en el caballo de batalla de los huelguistas. Eran las vías principales a través de las cuales acceder a la regularización ya que estaban previstas genéricamente en la ley y además se ajustaban al estado anémico de los 
encerrados de extrema debilidad, pues no en vano eran ya más de una docena de días de encierro, y sobre todo, en huelga de hambre. Así, el día 3 de febrero, sábado, y tras una larga reunión que finalizó a las cuatro de la mañana, los representantes de los encerrados, a quienes se les habían traducido todos los pormenores del acuerdo, y la Delegación del Gobierno suscribieron el preacuerdo ofrecido por el Síndic y se dio por concluida la huelga de hambre.

En el documento denominado las "Propuestas del Síndic de Greuges, en calidad de mediador, al Gobierno central y a las personas en huelga de hambre por su situación de irregularidad en nuestro país, encerradas en diversas iglesias de la diócesis de Barcelona", el Síndic solicitaba los siguientes movimientos para continuar con la negociación: por un lado, que los encerrados cesasen la huelga y así crear el clima de normalidad necesario para negociar, según demandaba el Secretario del Estado para la Extranjería; y por otro, que se cumpliesen diferentes requisitos por parte del Gobierno Central y de las Fuerzas y Cuerpos de Seguridad del Estado: no perseguir a los inmigrantes no vinculados a actividades delictivas, basándose únicamente en el hecho de encontrarse en situación irregular; no tramitar expulsiones durante los procesos de regularización en trámite; no expulsar a los extranjeros involucrados en procedimientos penales por falsificación documental en el proceso de regularización anterior (2000) mientras no existiera sentencia firme; garantizar la ausencia de cualquier tipo de represalia contra las personas y organizaciones que apoyaron la acción reivindicativa; considerar la posibilidad, por parte del Gobierno, de que la legislación vigente podría permitir una solución favorable a los expedientes rechazados en el procedimiento de regularización, al tiempo que, para las personas que no hubieran presentado solicitud en la regularización de 2000 y se encontraran en España, se podría regularizar su estancia conforme a las fórmulas previstas en la legislación (la concurrencia de razones humanitarias o circunstancias excepcionales).

No obstante, la presencia de un abogado de origen extranjero y miembro de la comisión negociadora como representante de los encerrados en la comisión jurídica que debía concretar el acuerdo alcanzado con la mediación del Síndic fue el argumento alegado por el Gobierno para continuar negociando, hecho que al mismo tiempo empujó a que el 9 de febrero el Síndic dimitiera como mediador.

"Lamentablemente no se ha conseguido un acuerdo en la composición de la comisión técnica. Los inmigrantes han señalado que están de acuerdo con la propuesta del Síndic, siempre y cuando en la comisión técnica participara como mínimo un miembro de la comisión negociadora. El Gobierno no ha aceptado que en la comisión técnica participara ninguno de los miembros de la comisión negociadora, por entender que supondría negociar mientras persiste el encierro. Por cuanto antecede [...] doy por concluida mi mediación". (Comunicado del Síndic de Greuges de 5 de febrero de 2001). 
La negociación final se realizó sin mediaciones, entre los representantes del Gobierno y un grupo de juristas que inspiraban confianza a los inmigrantes por su larga trayectoria tanto en la colaboración con los movimientos sociales como en la defensa de los derechos de grupos desfavorecidos ${ }^{14}$. La creación de lo que se denominó la Comisión Técnica Paritaria encargada de redactar el acuerdo final, así como de la intervención de organizaciones sociales vinculadas a la Iglesia como garantes ${ }^{15}$ del cumplimiento de lo pactado determinaron este tercer momento de las negociaciones.

Tras casi un mes desde el acuerdo del Síndic y ante la inminente firma de un acuerdo, el 7 de marzo casi mil inmigrantes desalojaban las once iglesias barcelonesas en las que llevaban encerrados 47 días.

Así, el día 8 de marzo de 2001 se firmaba el "Acuerdo de Barcelona", el primero de los acuerdos resolutivos alcanzados entre Gobierno e inmigrantes sin-papeles en el contexto de los encierros del 2001 en el estado español. Concretamente, el acuerdo constaba de 3 partes relacionadas con el proceso anterior de negociación. Una primera parte se basada en la propuesta formulada por el mediador del conflicto, el Síndic de Greuges; una segunda parte, era el fruto de la reunión de la denominada "comisión paritaria" en la que se desarrollan los compromisos recogidos en el segundo punto del acuerdo con el Síndic; y en tercer lugar, se incluía el anexo que ampliaba los supuestos y hacía un llamamiento a otras administraciones a que, en la medida de sus competencias, colaborasen en la integración social de los inmigrantes encerrados.

El resto de los principales encierros que se estaban llevando simultáneamente en el estado español, especialmente los de Murcia, Valencia, Andalucía y Madrid finalizaron sin ninguna duda, gracias a la resistencia de sus protagonistas, a la coordinación que existió entre los distintos encierros a través de la Coordinadora estatal de inmigrantes con y sin-papeles, pero especialmente a la cesión del Gobierno del Estado a aplicar casi idénticamente los acuerdos alcanzados en Barcelona. Como reconoció el entonces ministro de interior, Mariano Rajoy, en una comparecencia de prensa junto al defensor del pueblo, Enrique Múgica, los criterios de arraigo o razones humanitarias y estancia

\footnotetext{
${ }^{14}$ Los abogados Pep Manté y Matias Gríful pertenecian al Col-lectiu Ronda, una cooperativa de abogados y abogadas nacida en 1972 para el asesoramiento laboral y de seguridad social de trabajadoras y trabajadores y al asesoramiento antirrepresivo durante la Dictadura; Antonia Moyano llevaba años colaborando con algunas personas de la Asamblea Papers per a Tothom, concretamente con Norma Falconi en Portes Obertes (CGT), donde además de la asesoría jurídica, también planteaba estrategias de apoyo y defensa de los inmigrantes irregulares; y Elvira Posada había estado en otras luchas previas, apoyando a la Asamblea Papers per a Tothom desde la Comisión de Defensa de los derechos de la persona y del libre ejercicio de la abogacía, siendo una de las primeras iniciativas un informe que se elaboró desde la Comisión de Defensa que derivó en el recurso de inconstitucionalidad de la Ley de Extranjería de 1985.

${ }^{15}$ La ONG Justícia i Pau, que además contaba también con el apoyo de otras organizaciones como la Juventud Obrera Cristiana o la Unió de Religiosos de Catalunya, asumía, según el punto primero del documento, el papel de "garante del cumplimiento de los acuerdos consensuados, referentes a la regularización de dichos inmigrantes".
} 
desde el 23 de enero de 2001, que ya se habían aplicado a los grupos de inmigrantes que habían protagonizado encierros, se extenderían a todo el Estado "con la máxima flexibilidad" 16 en lo que se ha denominado posteriormente la regularización extraordinaria de junio del 2001, según la cual 334.882 inmigrantes lograron obtener los papeles. Se cumplía así la máxima de los encierros tal y como Norma Falconi, en representación de los sin-papeles, plasmó el 8 de marzo de 2001 en la firma de los Acuerdos de Barcelona:

\begin{abstract}
"Se iniciaron los encierros con una demanda: papeles para todos y todas y terminamos con la misma demanda. Por eso consideramos que estos acuerdos deben extenderse para todos los inmigrantes sin-papeles. Quienes han comprometido su vida en el encierro y la huelga de hambre no lo han hecho solo por ellos mismos sino por todas las personas que están en la misma situación".
\end{abstract}

\title{
CONCLUSIÓN
}

A partir de la narración de varios aspectos de los encierros de Barcelona en 2001 hemos tratado de reflexionar sobre la capacidad de los sin-papeles para devenir en sujetos colectivos con capacidad normativa. Sería excesivo concluir que los encierros modificaron en sentido formal normas jurídicas como la Ley de Extranjería vigente en ese momento. Sin embargo, esto no quiere decir que a nivel social y jurídico no se derivaran consecuencias con una trascendencia significativa.

Los encierros supusieron la consecución de una serie de metas jurídicas muy relevantes. En primer lugar, el gobierno se vio obligado a la implementación progresiva de acuerdos negociados directamente con los encerrados y sus representantes, convirtiendo así a sujetos repudiados jurídicamente, en interlocutores válidos, lo reconociera el Gobierno o no. En segundo lugar, el acuerdo modificó y sustituyó los términos legales de los procesos de regularización anteriores previstos en normas de rango legal y reglamentario, a todas luces insuficientes. Dicho con otras palabras, en la práctica se mejoraron preceptos legales restrictivos. Cientos de miles de inmigrantes en situación irregular adquirieron la regularidad gracias a las luchas de aquellos días. Al final, pese a la dificultad de establecer una relación de causa-efecto entre algunas de las cláusulas contenidas en los acuerdos y las posteriores reformas de la normativa de extranjería, especialmente en lo que refiere a violencia de género, circunstancias excepcionales, razones humanitarias 0 arraigo, no es nada despreciable el intenso

\footnotetext{
16 "El acuerdo Barcelona se extiende a toda España" (Diario La Vanguardia, 7 de junio de 2001); Según Rajoy, "Es la misma interpretación que ya se ha hecho en Valencia y en Cataluña, en todo el arco mediterráneo" (Diario El País, 7 de junio de 2001).
} 
debate que los acuerdos provocaron en cuanto a interpretación de estos conceptos se refiere. La labor que realizaron abogados y activistas sentaron un antes y un después en la cotidianeidad del batallar procesal en el Derecho de extranjería.

En definitiva, las luchas de los encierros generaron una expresión alternativa en el modo de concebir la "ciudadanía en acción", similar a la "ciudadanía insurgente" de Holston (1999), iniciaron el camino a la estatalización, e incluso, impulsaron una transnacionalización de la lucha por el reconocimiento de derechos de los migrantes (Barbero 2010). Por encima de las múltiples contradicciones que el movimiento de sinpapeles pudiera y pueda presentar en determinados aspectos, no hay duda de que en aquellos días se rompió la frontera de la invisibilidad de los inmigrantes en situación irregular, quienes al menos por un tiempo, redefinieron la estratificación cívica imperante (Morris 2002).

Lo anterior nos lleva a poder afirmar que, a pesar de la construcción jurídica, política y social del inmigrante irregular como carente de capacidad jurídica normativa, los sinpapeles, tanto en Barcelona como en otros lugares del resto del Estado, se constituyeron como sujetos colectivos autónomos y con capacidad de movilización social con un relevante impacto en la agenda normativa. Lo relevante de esta constitución como sujetos colectivos de juridicidad es que se produce a través de prácticas jurídicas alternativas, es decir, a través de actos (huelgas de hambre, manifestaciones, encierros, boicots, etc.) o bien no previstos en el ordenamiento jurídico como tal, o bien no reconocidos a personas en situación irregular en ese momento ${ }^{17}$.

A pesar de que esta obra enmarca un estudio de caso específico, podríamos decir que asistimos a un momento en el que los migrantes sin-papeles están emergiendo "desde los márgenes de la ciudadanía nacional" para generar cambios sociales políticos y jurídicos. Recordando lo que decían autores clásicos como lhering, en 1872 (2008), todo derecho ha sido logrado por la lucha. Clases, grupos sociales, colectivos marginados emergen como reclamantes de derechos, y aunque algunos son aplacados, otros logran dotar de un sentido alternativo a la ciudadanía. La Historia es pues, la constante irrupción de nuevos sujetos que algunas veces se sirven de herramientas que el Derecho les reconoce, pero en otras ocasiones inventan, crean 0 arrebatan los instrumentos que les permiten la reivindicación y puesta en práctica de sus demandas.

Así, en este artículo se ha pretendido presentar un modo de percibir la emergencia de ciertos colectivos, incluido el movimiento sin-papeles, no como meros agentes políticos, sino como sujetos con pretensiones de juridicidad. Como ha dicho Wolkmer,

${ }^{17}$ Entre el 7 de noviembre (STC 236/2007) y el 19 de diciembre de 2007 (STC 259/2007) se produjeron los fallos del Tribunal Constitucional español, según los cuales derechos fundamentales como el de reunión, asociación, sindicación, educación o asistencia jurídica gratuita, anteriormente negados por la legislación española de extranjería (LO 8/2000), pertenecen al ámbito de la "dignidad humana", y por tanto son reconocidos también a los inmigrantes en situación irregular desde su condición de persona. 
"en la medida en que los movimientos sociales son encarados, sea como sujetos depositarios de una nueva ciudadanía apta para luchar y hacer valer sus derechos ya conquistados, sea como nueva fuente de legitimación de la producción jurídica, nada más natural que equipararlos a la categoría de nuevos sujetos colectivos de Derecho" (2006:211).

Debemos concluir por tanto que mientras persista el modelo de control selectivo de las migraciones, lo que incluye la utilización de mano de obra barata, los sistemas de extranjería, la limitación de derechos y las fronteras para controlar el funcionamiento de ese sistema, tendrán lugar nuevos episodios de encierros, manifestaciones y huelgas motivados por la búsqueda de igualdad, libertad y justicia plena. Entre tanto aparecerán nuevos sujetos, nuevas demandas y nuevos métodos irrumpirán en la escena pública. Nuestra tarea, como observadores sociales es estar atentos y esforzarnos por captar las demandas de la ciudadanía y las subjetividades que las recorren. Si partiéramos del dogma de que el Derecho solo nace del Estado y sus instituciones, dejaríamos fuera de la investigación social y jurídica un número infinito de hechos protagonizados por actores no estatales pero con incuestionable relevancia jurídica. Es necesario por tanto adoptar una visión más allá de la formalidad jurídica o del legalismo para captar aquellos hechos producidos en los márgenes del derecho oficial y que, sin embargo, indudablemente son relevantes para la constitución de un nuevo paradigma social y jurídico.

\section{Agradecimientos}

Quisiera agradecer a todas aquellas personas que de alguna manera han contribuido al trabajo del cual se deriva este artículo, especialmente a Cristina Blanco y a Javier de Lucas; así como a las evaluaciones externas designadas por la RIS por sus sugerentes objeciones y recomendaciones. La investigación sobre la que versa este texto fue financiada por el Programa de ayudas para la formación de Investigadores (2005-2009) del Departamento de Educación, Universidades e Investigación del Gobierno VascoEusko Jaurlaritza; así como por una beca posdoctoral concedida por el Vicerrectorado de Ordenación Académica de la UPV-EHU (2010) para la difusión de los resultados obtenidos a través de diversas publicaciones.

\section{Referencias Bibliográficas}

Aierbe, P. 2000. “¿Hacia un movimiento europeo de sin-papeles?.” Mugak 6, Pp. 7-12.

Aja, E. y J. Arango. Veinte años de inmigración en España: perspectiva jurídica y sociológica (19852004). Barcelona: CIDOB. 
Ariza, Libardo y D. Bonilla. 2007. "El pluralismo jurídico. Contribuciones, debilidades y retos de un concepto polémico". Pp. 19-85 en Pluralismo Jurídico, editado por B. Tamanaha, S. Engle Merry y J. Griffiths. Bogotá: Siglo del Hombre Editores - Universidad de los Andes - Instituto Pensar.

Balibar, E. 2005. Violencias, identidades y civilidad. Para una cultura politica global. Barcelona: Gedisa.

Benhabib, S. 2004. The Rights of Others: Aliens, Residents, and Citizens. Cambridge: Cambridge University Press.

Bergalli, R. 1992. "Usos y riesgos de categorías conceptuales ¿Conviene seguir empleando la expresión uso alternativo del derecho?." El otro derecho 10:5-32.

Blanco, C. 2003. "Avances para la creación de una política común de inmigración y asilo en la UE" en Blanco, C (dir.)La inmigración en la UE : situación y perspectivas para Euskadi, Pp. 23-34.

Blanco, C. 2006 "Las imágenes de la inmigración en España. Apuntes en torno a una realidad que se debate entre lo real y lo imaginario" en Igartua, J.J. y Muñiz ,C. (Eds.) Medios de comunicación, inmigración y sociedad. Salamanca, Ed. Universidad de Salamanca (89-110).

Boaventura de Sousa, S. y C. Rodríguez Garavito. 2007. El derecho y la globalización desde abajo. Hacia una legalidad cosmopolita. Barcelona: Anthropos Editorial.

Bosniak, L. 2008. The Citizen and the Alien: Dilemmas of Contemporary Membership. New Jersey: Princeton University Press.

Burgos, G. 1996. "Los servicios legales populares y los extravíos de la pregunta por lo político." El Otro Derecho 21:9-25.

Calavita, K. 2005. Immigrants at the Margins: Law, Race, and Exclusion in Southern Europe. New York: Cambridge University Press.

Carvalho, A. 1992. Magistratura e directo alternativo. Sao Paolo: Editora académica.

Carvalho, A. 1997. "Direito Alternativo: Uma Revisita Conceitual." Justiça e Democracia 3:129-140.

Checa y Olmos, F. 2001 (Dir). El Ejido: la ciudad-cortijo. Claves socioeconómicas del conflicto étnico. Barcelona: Icaria Antrazyt.

Cissé, M. 2000. Palabra de sin-papeles. Donostia: Gakoa-Tercera Prensa.

Coutin, S. 2000 Legalizing Moves: Salvadoran Immigrants' Struggle for U.S. Residency. Ann Arbor: University of Michigan Press.

De Lucas, J. 1992. "Los operadores jurídicos: un problema de aplicación del derecho". Pp. 189-204 en Sentido y razón del Derecho: Enfoques socio-jurídicos para la sociedad democrática, coordinado por R. Bergalli. Barcelona: Editorial Hacer.

De Lucas, J. 2002. "Sobre las políticas de inmigración en la Unión Europea un año después del 11 de septiembre de 2001: inmigración, derechos, ciudadanía." Cuadernos Electrónicos de Filosofía del Derecho 6. 
De Lucas, J. 2008. "Discursos de lo invisible. Construir la presencia de los inmigrantes." en Los otros entre nosotros Alteridad e inmigración. VV.AA. Madrid: Círculo de Bellas Artes.

Ehrlich, E. 2005. Escritos sobre sociología y jurisprudencia. Madrid-Barcelona: Marcial Pons.

Facchi, A. 1994. "Pluralismo giuridico e società multietnica: Proposte per una definizione." Sociologia del Diritto 21:47-57.

Feixas, M. 2007. "Migration Movements between Pakistan and South Western Europe: Pakistani migratory networks in Catalonia". Tesis doctoral, Universidad Autónoma de Barcelona, Barcelona.

Galanter, M. 1981. "Justice in Many Rooms: Courts, Private Ordering, and Indigenous Law." Journal of Legal Pluralism and Unofficial Law 19:17-21.

Griffiths, J. 1986 "What is Legal Pluralism?." Journal of Legal Pluralism 24:1-55.

Grossi, P. 1996. El orden jurídico medieval. Madrid: Marcial Pons.

Hammar, T. 1990. Democracy and the nation states: aliens, denizens and citizens in a world of international migration. Avebury: Aldershot.

Herrera, J. y D. Sánchez. 1993. "Aproximación al derecho alternativo en Iberoamérica." Jueces para la democracia 20:87-93.

Hobbes, T. 1980. Leviatán: o la materia, forma y poder de una república, eclesiástica y civil. México: Fondo de Cultura Económica.

Holston, J. 1999. "Spaces of Insurgent Citizenship". Pp. 155-176 en Cities and Citizenship, edited by J. Holston. Durham and London: Duke University Press.

Huysmans, J. 2000. "The European Union and the securitization of migration." Journal of Common Market Studies 38:751-777.

Ihering, R. 2008. La lucha por el derecho. Granada: Comares.

Isin, E. 2002. Being Political: Genealogies of Citizenship. Minnesota: University of Minnesota Press.

Kelsen, H. 1991. Teoría Pura del Derecho. Introducción a la ciencia del Derecho. Buenos Aires: Uedeba.

Krueger, Laura. 2001. "El movimiento de los sin-papeles en Francia en los años noventa y sus reflejos en España." Revista Electrónica de Geografía y Ciencias Sociales 94.

Laubenthal, B. 2005. "La emergencia de las protestas de inmigrantes sin-papeles en España: el caso de la Región de Murcia". Pp. 159-174 en La condición inmigrante: exploraciones e investigaciones desde la Región de Murcia, coordinado por M. Hernández Pedreño y A. Pedreño Cánovas. Murcia: Universidad de Murcia.

Laubenthal, B. 2007. "The Emergence of Pro-Regularization Movements in Western Europe." International Migration 45, pp. 101-133. 
Locke, J. 1998. Segundo tratado sobre el Gobierno civil. Madrid: Alianza editorial.

Majuelos, Paco. 2000. "El Ejido, Balance". Mugak 11. (Disponible en http://revista.mugak.eu/articulos/ show/75)

Malinowsky, B. 1969. Crimen y costumbre en la sociedad salvaje. Barcelona: Ariel.

Martínez Veiga, U. 2001. El Ejido: discriminación, exclusión social y racismo. Madrid: Los Libros de la Catarata.

Martínez Veiga, U. 2004. Trabajadores invisibles: precariedad, rotación y pobreza de la inmigración en España. Madrid: Libros de la Catarata.

Massó Garrote, M. 2001. "La nueva regulación del derecho de extranjería en la Ley Orgánica 8/2000, de 22 de diciembre de reforma de la Ley Orgánica 4/2000, de 11 de enero, sobre derechos y libertades de los extranjeros en España y su integración social", Actualidad administrativa 11:241-259.

Merry, S. 1979. "Going to Court: Strategies of Dispute Management in an American Urban Neighborhood." Law \& Society Review 13:891-925.

Merry, S. 1988. "Legal Pluralism." Law \& Society Review 22:869-896.

Monclús, M. 2004. "La Europa Fortaleza y los excluidos del proyecto constitucional". Pp. 105-122 en La ilusión constitucional. Una crítica del proyecto de la Convención y razones para una Europa alternativa, editado por X. Pedrol y G. Pisarello. Madrid: El Viejo Topo.

Montalbán López, F. 2003. Inmigrantes en lucha. Región de Murcia 2001. Murcia: Contrastes-El Foro Ignacio Ellacuria.

Moore, S. F. 1973. "Law and social change: the semi-autonomous social field as an appropriate subject of study." Law and Society Review 7:719-746.

Morris, L. 2002. Managing Migration. Civic Stratification and Migrants' Rights. Londres: Routledge.

Moya, D. 2006. "La evolución del sistema de control migratorio de entrada en España". Pp. 47-84 en Veinte años de inmigración en España: Perspectiva jurídica y sociológica (1985-2004), editado por E. Aja y J. Arango. Barcelona: CIDOB.

Nyers, P. 2008. No One Is Illegal Between City and Nation. Engin F. Isin and Greg M. Nielsen. Eds. Acts of Citizenship. Zed Books.

Palacio, G. 1993. Pluralismo Jurídico: El Desafí al Derecho Oficial. Bogotá: Universidad Nacional de Colombia.

Pedone, C. 2005. Diversificación de las cadenas migratorias ecuatorianas hacia el mercado de trabajo agrícola en Murcia". Pp. 255-272 en La condición inmigrante: exploraciones e investigaciones desde la Región de Murcia, coordinado por M. Hernández Pedreño, A. Pedreño Cánovas. Murcia: Universidad de Murcia.

Pospisil, Leopold. 1971. Kapauku Papuans and their Law. New Haven: Yale University publications in anthropology. 
Rea, A. 2006. "La europeización de la política migratoria y la transformación de la otredad", Revista española de investigaciones sociológicas 116:157-184

Rech, Daniel. 1990. "El Derecho insurgente. El Derecho de los oprimidos". El otro Derecho 6:3-5.

Sagarra, E. 2001. "Los derechos políticos y públicos de los extranjeros en la Ley Orgánica 8/2000 de 22 de diciembre de 2000", Cuadernos de derecho judicial 8:39-68.

Santos, B. 1977. "The Law of the Oppressed: The Construction and Reproduction of Legality en Pasárgada", Law \& Society Review 12:2-126.

Santos, B. 1992. "El derecho en la Favela. Notas sobre la historia jurídico-social de Pasárgada", Revista No hay derecho 6:17-19.

Santos, Boaventura de Sousa. 1977. "The Law of the Oppressed: The Construction and Reproduction of Legality en Pasárgada." Law \& Society Review :2-126.

Schuck, P. H. 1998. Citizens, Strangers and In-betweens. Essays on Immigration and Citzenship. Boulder: Westview Press.

Silveira, H. 2003. "Inmigración y derecho: la institucionalización de un sistema dual de ciudadanía". Pp. 539-576 en Sistema penal y problemas sociales, coordinado por R. Bergalli.

Solanes, A. 2009. "La apertura selectiva: nacionalidad y mercado frente a la movilidad humana". Pp. 67-96 en La igualdad en los derechos: claves de la integración, coordinado por J. de Lucas. Madrid: Dykinson.

Suárez, L., R. Macià y Á. Moreno. 2008. Las luchas de los sin-papeles y la extensión de la ciudadanía. Perspectivas críticas desde Europa y Estados Unidos. Madrid: Traficantes de sueños.

Terray, E. 1999. "Le travail des étrangers en situation irréguliêre ou la dèlocalisation sur place". Pp. 9-34 en Sans papiers: l'archaïsme fatal, editado por E. Balibar, E. Terray, M. Chemillier-Gendreau y J. Costa-Lascoux. París: La Découverte.

Treves, R. 1988. Sociología del Derecho: orígenes, investigaciones y problema. Barcelona: Ariel Derecho.

Weber, Max. 1984. Economía y Sociedad. México: Fondo de Cultura Económica.

Wolkmer, A.C. 1991. "Pluralismo jurídico y movimientos sociales." El Otro Derecho 7.

Wolkmer, A.C. 1994. Pluralismo jurídico. Fundamentos de uma nova cultura no Direito, São Paulo: Alfa-Omega.

Wolkmer, A.C. 2006. Pluralismo Jurídico: Fundamentos de una nueva cultura del Derecho. Sevilla: Editorial MAD.

IKER BARBero es Doctor por la Universidad País Vasco-Euskal Herriko Unibertsitatea e International Master in Sociology of Law por el International Institute of Sociology of Law. En la actualidad es contratado doctor por Ikerbasque, the Fundation for Science (2011-2013) y Visiting Scholar en 